\title{
FACTORING: UMA OPÇÃO DAS MICROS E PEQUENAS EMPRESAS AOS CUSTOS FINANCEIROS, DE INADIMPLENCIA E GERENCIAIS? ${ }^{1}$
}

\section{FACTORING: AN OPTION OF THE SMALL ENTERPRISES AT THE FINANCIAL COSTS, OF BREACH OF CONTRACT AND MANAGERIAL?}

\author{
Luiz Claudio Otranto Alves ${ }^{2}$ \\ Marcia Castro Silva ${ }^{3}$ \\ José Ricardo Maia de Siqueira ${ }^{4}$
}

\begin{abstract}
RESUMO: O factoring moderno iniciou suas atividades no Brasil na década de 1980, com a proposta de auxiliar o pequeno empresário com a compra de créditos, assumindo riscos, e a prestação de diversos outros serviços de apoio. Tornou-se, portanto, uma opção para reduzir os custos financeiros, de inadimplência e, até mesmo, gerenciais de seus clientes. Esta pesquisa exploratória foi desenvolvida com o objetivo principal de verificar se atualmente, na prática, a atuação das empresas de factoring traz benefícios às micros e pequenas empresas, através da redução dos custos acima elencados. $\mathrm{O}$ universo estudado ficou circunscrito às gráficas situadas no Grande Rio, justificado por se tratar de um segmento do setor de maior atuação das factorings, que é a indústria, e a amostra foi não probabilística, definida por acessibilidade. Os resultados revelaram que a maioria das empresas consultadas não tem acesso aos serviços de apoio que deveriam estar sendo oferecidos pelas factorings. Apenas ocorre o provimento de recursos, sem assunção de riscos pela inadimplência do devedor e com custos mais elevados do que as operações efetuadas pelas instituições financeiras.
\end{abstract}

Palavras-chave: Factoring. Custos financeiros. Cessão de créditos.

\begin{abstract}
The modern factoring began their activities in Brazil in the decade of 1980, with the proposal of aiding the small entrepreneur with the purchase of credits, assuming risks, and the installment of other several support services. Therefore, it became an option to reduce the financial costs, of breach of contract and, even, managerial of their customers. This exploratory research was developed with the main objective of verifying nowadays, in practice, the performance of the factoring companies brings benefits to the small enterprises, through the reduction of the costs. The studied universe was bounded to the graphs located in Great Rio, justified for treating of a segment of the sector of larger performance of the factorings (the industry) and the sample was no probabilistic, defined for accessibility. The results revealed that most of the consulted enterprises don't have access to the support services that should be being offered by the factorings. They just offer the provision of resources, without assumption of risks for the debtor's breach of contract and with higher costs than the operations made by the financial institutions.
\end{abstract}

Key-words: Factoring. Financial costs. Cession of credits.

\footnotetext{
${ }^{1}$ Artigo Recebido em 17.10.2007 . Revisado por pares em 17.11.2008 . Recomendado em 26.02.2009 por Denise Del Pra Netto Machado (editora). Publicado em 22.04.2009.

Organização Responsável pelo periódico: Universidade regional de Blumenau - FURB - www.furb.br/rn
}

\footnotetext{
${ }^{2}$ Universidade Federal do Rio de Janeiro - luizotranto@hotmail.com

${ }^{3}$ Universidade Federal do Rio de Janeiro - marcia cs@hotmail.com

${ }^{4}$ Universidade Federal do Rio de Janeiro - jirms@, facc.ufrj.br
} 


\section{Introdução}

Baseado no estudo de Hillyer (1941) e Salamacha (2004), pode-se constatar que os factors da antiga Babilônia, Grécia e Roma prestavam serviços de comercialização, distribuição e administração. Isto porque os agentes daquela época - em que não havia circulação de moedas - caracterizavam-se por serem profundos conhecedores do mercado. Estudo elaborado por Silva (1995) mostra que somente a partir da Revolução Industrial, com o desenvolvimento das colônias inglesas na América do Norte, os factors passaram a incorporar a função de fornecedor de recursos, dando origem a uma atividade mais parecida com o factoring que é praticado na atualidade.

Banerjee (2003) aponta a importância do factoring como suporte para dar sustentabilidade às pequenas e médias empresas, destacando também a representatividade do negócio de factoring tanto em economias desenvolvidas, como em desenvolvimento. Ao mencionar o grau de maturidade para a indústria do factoring na Europa e nas Américas, avença a possibilidade de atuar como agente de crédito, contabilidade e cobrança.

No contexto brasileiro, Salamacha (2004) afirma que o maior nicho de atuação das empresas de factoring é o das pequenas e médias empresas. Um estudo do IBGE (2003) mostra que as micros e pequenas empresas - MPEs adquiriram importância na economia a partir do cenário inflacionário e de desemprego dos anos 80 , quando foi vislumbrado o potencial gerador de emprego deste segmento, que teve o acesso ao crédito restringido na década de 90 em decorrência da estabilização macroeconômica proporcionada pelo Plano Real. Naquela ocasião, as receitas inflacionárias exorbitantes deixaram de existir, levando os bancos a aperfeiçoarem o seu gerenciamento de riscos como forma de mitigar a perda de rentabilidade.

Aliado a isto, pesquisa realizada pelo SEBRAE (2004) mostra que os fatores responsáveis pela elevada mortalidade das pequenas empresas estão, preponderantemente, relacionados à fragilidade gerencial.

O papel que o factoring tem no auxílio a estas empresas é fazer o pequeno empresário "sentir-se aliviado de uma série de preocupações no que tange ao provimento de recursos e administração financeira” (LEITE, 2005, p. 6). A Associação Nacional das Empresas de Fomento Mercantil Factoring (ANFAC) foi fundada em 1982 e teve logo o primeiro grande desafio de deixar bem claro quais os objetivos e as vantagens para o seu mercado-alvo; principalmente porque, naquele momento, o Banco Central considerava a atividade das factorings equiparada com a de instituições financeiras (BANCO CENTRAL DO BRASIL, 1982).

Daí surgiu o pressuposto básico da operação de factoring no Brasil adotado pela ANFAC: serviços de apoio à sua clientela (ex: organizar a contabilidade, controlar o fluxo de caixa, acompanhar as contas a receber e a pagar etc), consubstanciando uma relação de parceria entre o Agente de Fomento Mercantil e suas empresas-clientes, "com elas mantendo estreito, e até diário, contato" (LEITE, 2005, p. 7). Segundo o mesmo autor, toda essa gama de serviços justifica-se para facilitar a compra de créditos pela factoring.

Não obstante o fato das empresas de factoring não intermediarem recursos financeiros, observa-se que o fim da equiparação do factoring à atividade bancária (BANCO CENTRAL DO BRASIL, 1988) teve forte contribuição da prestação de serviços de apoio e assunção dos riscos decorrentes à compra dos créditos.

Entretanto, tem-se observado que a inexistência de uma regulamentação consolidada para a atividade dá margem para que a atuação das empresas de factoring assuma diversas formas; algumas, no mínimo, questionáveis. São elas: 
- A inexistência da prestação de serviços de apoio, concomitantemente à venda de faturamento de uma empresa à outra; e

- O factor se exime do risco dos créditos adquiridos, obrigando sua empresa-cliente a se responsabilizar pela eventual inadimplência do devedor.

Este trabalho parte da constatação de que "ninguém pode ser obrigado a fazer ou deixar de fazer alguma coisa senão em virtude da lei", presente no artigo $5^{\circ}$ da Constituição Federal (BRASIL, 1988); por isso, a inexistência de uma lei específica para o fomento mercantil em nosso país, pode colaborar para uma desvirtuação da atuação desta atividade para algo, não necessariamente ilegal, mas distante da sua origem histórica e cada vez mais próxima da atividade bancária (ainda que não possa ser enquadrada como tal).

O objetivo principal desta pesquisa é analisar as características das operações de factoring, visando verificar se, na prática, as factors fornecem um serviço capaz de impactar positivamente os custos financeiros (através do oferecimento de uma opção mais barata às operações bancárias), os custos de inadimplência (através da assunção dos riscos inerentes aos créditos adquiridos) e os custos gerenciais (através da prestação de serviços de apoio assessoria e/ou gestão - à sua clientela).

\section{Metodologia}

No momento em que aborda a importância dos diversos serviços oferecidos pelas factorings às micros e pequenas empresas, este artigo utiliza-se do conceito lato de custos, que engloba todos os recursos renunciados ou sacrificados para conseguir um determinado objetivo (HORNGREN et al, 2005).

Quanto aos aspectos metodológicos e meios de investigação o estudo é exploratório e bibliográfico, segundo a classificação feita por Vergara (2003). Exploratório porque há pouco conhecimento acumulado e sistematizado sobre a importância do factoring na administração das micros e pequenas empresas; por isso, mediante a aplicação de um questionário em empresas do setor produtivo carioca, busca aferir, na prática, como são os serviços prestados pelas empresas de factoring. A pesquisa bibliográfica é justificada pela importância do embasamento teórico do assunto tratado, bem como pela necessidade de se estar atualizado quanto aos recentes artigos científicos, dissertações, jurisprudência e normatização da atividade; além da consulta aos sítios especializados e pela busca de informações em periódicos que abordem o direito do fomento mercantil.

Quanto à pesquisa exploratória realizada, foram desenvolvidas questões conforme os objetivos declarados, de forma que permanecessem associadas a estes, e que mantivessem uma estreita relação com o conteúdo da revisão de literatura.

Responderam o questionário elaborado indústrias gráficas localizadas no Grande Rio, delimitando-se, com isso, o universo da pesquisa, justificado por se tratar de um segmento do setor de maior atuação das factorings, que é a indústria. Segundo Kumar (2005), as empresas de fomento mercantil já possuem um conjunto de empresas-clientes entre diversos setores de atuação: indústria (65\%), comércio (20\%) e serviços (15\%).

Para compor a amostra, não probabilística, definida por acessibilidade (VERGARA, 2003), foram consultadas micros e pequenas empresas, legalmente constituídas, a fim de que respondessem o questionário elaborado. Inicialmente enviados pela internet, com baixo índice de retorno, os questionários passaram a ser aplicados nas sedes das empresas e pelo telefone. De acordo com a ANFAC, em 2006, as gráficas representaram o quarto segmento industrial brasileiro com maior participação no giro da carteira do fomento mercantil. Assim, entende-se 
que o grupo pesquisado constitui parâmetro aceitável para que sejam verificados os serviços oferecidos pelas empresas de factoring.

O enfoque utilizado possui como limitação o fato de não poder (nem pretender) generalizar os resultados obtidos para atividade de factoring como um todo, mas apenas verificar indícios de sua real atuação.

\section{Revisão de literatura}

3.1 Histórico mundial - Hillyer (1941) afirma que, etimologicamente, a palavra factoring, tem sua origem no substantivo latino factor, da mesma família do verbo facere, que tem como significado agir, fazer, desenvolver e fomentar. Factor, concluindo, seria aquele que faz alguma coisa que desenvolve ou fomenta uma atividade.

A origem da figura jurídica e do agente da prática do fomento mercantil confunde-se com a própria origem do comércio. Hillyer (1941) deduz isso ao definir a figura do agente mercantil como contemporânea a da própria história da civilização, encontrando a expressão factoring no "Código de Hamurabi" que possuía, dentre outras coisas, fórmulas de gestão comercial e normas que regulamentavam os procedimentos do comércio na antiga Babilônia.

Salamacha (2004) informa que os factors eram profundos conhecedores dos mercados, por isso, agiam como intermediários nas trocas comerciais, guardando e vendendo mercadorias. Esta forma de atuação iniciou-se na Grécia e em Roma e difundiu-se até a Idade Média.

Em função dos grandes descobrimentos, que proporcionaram a expansão do comércio, os factors desenvolveram-se largamente nos países colonizadores, como Inglaterra, Holanda, Espanha, França e Portugal. Um exemplo citado por Corrêa (2004) cita as "factorias" como empórios, armazéns de mercadorias que serviam como centros polarizadores entre as metrópoles e as colônias.

Especificamente no relacionamento entre as colônias americanas e a Inglaterra, o crescimento populacional aumentou o comércio, o que também impulsionou a atividade de factoring. Segundo Silva (1995), com a Revolução Industrial, a indústria têxtil inglesa foi fortemente impulsionada pela mecanização, e a produção em larga escala possibilitou um maior fluxo de produtos para as colônias. Com o desenvolvimento da colônia, os factors passaram a atuar tanto na Europa quanto na América do Norte e, além de serem responsáveis pela intermediação das vendas, armazenamento das mercadorias e cobrança dos créditos, passaram também a antecipar recursos para os proprietários das mercadorias.

Neste contexto surgiu o que Leite (2005, p. 3) chama de "sentido moderno de factoring". Segundo o mesmo autor (2005, p. 3): o "factor, que no seu sentido primitivo prestava serviços de comercialização, distribuição e administração, agregou a função de fornecedor de recursos".

Com o final da Guerra Civil americana, a atividade de factoring experimentou novas mudanças em sua forma de atuar. A mudança na dinâmica das relações entre Europa e América do Norte trouxe uma nova situação onde as empresas de factoring: "adiantavam fundos em relação à recebíveis, cobravam, mantinham a contabilidade e assumiam riscos" (SILVA, 1995, p. 23).

Segundo Leite (2005), apesar da origem das operações de factoring no contexto norteamericano ter sido realizada por meio de sua metrópole na época colonial; no século XIX, cessaram as atividades de factoring na Inglaterra, as quais só retornaram no século seguinte, na década de 1960, por meio de empresas americanas. Com isso, o mesmo autor informa que o factoring, no final do século XIX, tornou-se um fenômeno tipicamente americano e bastante 
requisitado pelos produtores do Oeste, "desejosos de aumentar as vendas sem expor-se a muitos riscos e sem endividar-se" (LEITE, 2005, p. 285).

O factoring desenvolveu-se principalmente no setor produtivo. De acordo com Corrêa (2004, p. 21), "nos Estados Unidos, até as primeiras três décadas do século XX, o factoring estava direcionado às manufaturas de algodão, lã e indústria têxtil". $\mathrm{O}$ mesmo autor relata que a atividade expandiu-se para outras indústrias (móveis, sapatos, plásticos, produtos químicos, couro, desenhos, brinquedos e eletrodomésticos) graças à crise monetária de 1931 e depois à bancária de 1933, quando assegurou os recursos que os bancos estavam impossibilitados de suprir.

Baseando-se na obra de Gremaud, Vasconcelos e Toneto (2002), observa-se que o contexto econômico do pós Segunda Guerra, caracterizado pelo financiamento da reconstrução dos países beligerantes, através do Plano Marshall, aliado à concepção institucional criada em Bretton Woods, evidenciou o domínio norte-americano, tanto no âmbito financeiro, quanto no produtivo. O comércio internacional auxiliou o forte crescimento econômico, tendo como peça-chave os Estados Unidos, que disseminaram seus padrões econômicos, promovendo uma fase de importante desenvolvimento tecnológico. Os mesmos autores continuam afirmando que nos anos 1960, com restrições impostas pelo FED, os bancos americanos, interessados em ampliar seus negócios, e fomentados pelo período de liqüidez internacional, instalaram-se no mercado europeu, criando o chamado Euromercado. Sob esse ambiente de prosperidade e expansão econômica, difundiram-se, em outras economias, padrões norte-americanos de produção e tecnologia, entre eles, a atividade de factoring.

Segundo Dodl (2006) estabeleceram-se pela Europa, a partir dos anos 1960, empresas de factoring, cujo desenvolvimento se deu de acordo com as particularidades de cada país, sendo que na Inglaterra, com a proximidade do idioma, houve rápida adaptação. Corrêa (2004, p. 27) aprofunda-se mais ao afirmar que na década de 60, o First National Bank, americano, "implanta um projeto de factoring como forma de auxiliar as transações de comércio internacional entre EUA e países da Europa". Isto representou o retorno do factoring à Europa após o período de descontinuidade da atividade no velho continente.

O cenário atual do fomento mercantil na Europa é marcado por uma grande participação do setor bancário, onde os "principais serviços oferecidos (...) são: cobertura de riscos, cobrança e fomento às empresas-clientes" (CORRÊA, 2004, p. 27).

Sobre o retrospecto recente nos Estados Unidos, Mahar (1984) informa que o domínio dos bancos, no início da década de 1960, proporcionou uma onda de respeitabilidade à atividade e contribuiu para o desenvolvimento da eficiência operacional, necessária para introduzir o factoring em outros ramos da indústria; entretanto, os bancos passaram a se desinteressar pela atividade, que exigia um relacionamento mais estreito, com acompanhamento diário e confiança no cliente; bem diferente de fazer grandes empréstimos a poucos tomadores.

Quanto à diferença básica entre a atividade de factoring desenvolvida nos Estados Unidos e no Canadá, Silva (1995) afirma que, apesar de no Canadá a atividade também ter surgido no período colonial, atualmente, a maioria das suas empresas não adianta recursos para suas empresas-clientes. Segundo o autor, elas atuam prioritariamente nas áreas de garantia de crédito, serviços de cobranças e contabilidade.

Levantamento recente feito pelo Factor Chain International (FCI) mostra o crescimento do factoring em escala mundial, com um volume negociado passando de $€ 623,8$ bilhões em 2000 para $€ 1.134,3$ bilhões em 2006 (aumento de 81,8\%). Atualmente, esta atividade encontra-se mais concentrada na Europa (mais de $70 \%$ do total mundial), 
principalmente no Reino Unido, Itália e França. A Ásia (13,2\%) e as Américas (12,4\%) vêm em seguida, com o Japão os Estados Unidos responsáveis, respectivamente, pelo maior volume de negócios nesses continentes. Verifica-se, com isso, o forte crescimento da atividade nos países desenvolvidos (FCI, 2007).

$\mathrm{O}$ avanço tecnológico e os acordos comerciais vêm contribuindo para o desenvolvimento do factoring internacional, inclusive nos países da Ásia, Oceania e América Latina. Conforme Leite (2005), uma minuta de contrato de factoring foi aprovada na Convenção Diplomática de Ottawa, no Canadá, em 1988, promovida pelo UNIDROIT (Institut International pour l'Unification $d u$ Droit Prive - Instituto Internacional para Unificação do Direito Privado), quando houve a participação de 53 países (o Brasil também esteve presente). Até o momento da realização desta pesquisa, a homologação do acordo havia sido realizada na Alemanha, França, Inglaterra e Itália.

3.2 Histórico no Brasil - Segundo Dodl (2006) e Leite (2005), o aparecimento do factoring no Brasil está associado à descoberta, durante uma inspeção realizada pelo Banco Central do Brasil em 1968, de uma rubrica denominada como "factoring" rasurada, no balancete de um banco de investimento em São Paulo. A partir de então, teve início o processo de pesquisa a respeito do assunto, tendo como referência um seminário realizado em Brasília, para bancos de investimentos, em 1979. Era o primeiro evento promovido pelo setor público em que se mencionava o factoring.

Naquela época, já estava em vigor a Lei n. 4.595/64 (BRASIL, 1964), que em seu artigo 18 consta: as "instituições financeiras somente poderão funcionar no País mediante prévia autorização do Banco Central da República do Brasil ou decreto do Poder Executivo, quando forem estrangeiras". Baseada neste dispositivo legal, a Diretoria do Banco Central emitiu a Circular n. 703/82 que, considerando as operações de factoring com "características e particularidades próprias daquelas privativas de instituições financeiras autorizadas pelo Banco Central" (BANCO CENTRAL DO BRASIL, 1982), passou a exigir todos os trâmites necessários à constituição de um estabelecimento financeiro; ou seja, não bastava o registro perante as Juntas Comerciais.

No mesmo ano de 1982, o factoring surge institucionalmente no Brasil com a criação da Associação Nacional de Factoring (ANFAC) que, segundo Leite (2005), tem por finalidade divulgar os verdadeiros conceitos do factoring, como mecanismo sócio-econômico, de apoio gerencial e financeiro, sobretudo para as empresas de pequeno e médio porte.

Neste momento, segundo Donini (2002, p. 739), as empresas de factoring, visando demonstrar à sociedade, e principalmente às autoridades, o importante papel social que exerciam junto às pequenas e médias empresas, procuraram salientar a prestação de serviços que elas desenvolviam, para afastar a não desejada comparação com atos de agiotagem e práticas características de instituições financeiras. Ainda segundo o mesmo autor, naquele mesmo momento, o factor também passou a assumir todos os riscos pela insolvência do devedor.

Esta postura adotada pela atividade de factoring contribuiu consideravelmente para que a circular n. 1.359/88 (BANCO CENTRAL DO BRASIL, 1988) revogasse a circular $n$. 703/82, bem como para que, em 1986, o então Tribunal Federal de Recursos decidisse, de forma unânime e irrecorrível, que o factoring se tratava de atividade essencialmente comercial. O factoring passava, então, a ser reconhecido como atividade comercial, disciplinada juridicamente pelos princípios do direito mercantil.

Nota-se, portanto, que o factoring trata-se de atividade consolidada no país, contando, inclusive, com entidade que congrega suas empresas, denominada como Federação Brasileira de Factoring (FEBRAFAC). Criada em fevereiro de 1993, com personalidade jurídica 
própria, reúne 18 sindicatos filiados. A FEBRAFAC - entidade sindical de nível superior - e a ANFAC - sociedade civil - têm como objetivo a defesa dos legítimos interesses dos empresários de factoring filiados e possuem, em comum, uma única estrutura administrativa e funcional.

Observando os dados recentes publicados no sítio do FCI (2007) o Brasil é o segundo maior mercado das Américas, com volume total de $€ 20,054$ bilhões em 2006, praticamente estável em relação a 2005, quanto movimentou $€ 20,050$ bilhões; mas sua participação no mercado mundial caiu de 1,92\% em 2000 para 1,77\% em 2006.

3.3 Modalidades - Para uma melhor compreensão das diversas modalidades, torna-se importante definir os quatro serviços básicos que poderão compor, segundo Donini (2002), uma operação de factoring:

- cessão de crédito - meio de transmissão dos títulos de crédito adquiridos do cedente-faturizado (empresa-cliente) pelo cessionário-faturizador (factoring). A remuneração do faturizador é a comissão ("fator") sobre o valor de face do título cedido, que tem como fato gerador a cessão de crédito;

- prestação de serviços convencionais - avaliação de fornecedores e clientes, acompanhamento de contas a receber e a pagar, organização contábil, controle do fluxo de caixa, de estoques, análise de crédito etc. Neste caso, a remuneração varia entre $0,5 \%$ e $3 \%$, com base no valor de face dos títulos cedidos (ad valorem);

- prestação de serviços diferenciados - gestão empresarial global ou em apenas alguns setores da empresa, co-gestão etc. A remuneração será estipulada livremente, podendo, por exemplo, ter como base de cálculo o faturamento da empresa; e

- antecipação de recursos não financeiros - este serviço não envolve recursos financeiros, mas matéria-prima/insumo para produção e estoque. A remuneração é estipulada com base na venda do produto, sendo que o faturizado também tem a exclusividade para aquisição dos títulos.

Brasil:

Donini (2002) elenca as seguintes modalidades domésticas de factoring praticadas no

- convencional: esta modalidade, segundo o autor, é a mais praticada no País e ocorre a cessão de crédito e a prestação de serviços convencionais;

- maturity: similar ao convencional (com cessão de crédito e prestação de serviços convencionais), sendo que o faturizador fornece os recursos financeiros ao faturizado no vencimento dos títulos;

- trustee: ocorre apenas a prestação de serviços diferenciados, portanto, não há fornecimento de recursos financeiros ao faturizado;

- matéria-prima: ocorre apenas a antecipação de recursos não financeiros; e

- importação-exportação: ocorre a cessão de crédito e a prestação de serviços convencionais, sendo que a operação é intermediada por duas empresas de factoring (uma de cada país envolvido), que garantem a operacionalidade e liquidez do negócio.

3.4 Conceito e caracterização - Estudadas as diversas modalidades e os serviços que cada uma engloba, esta seção propõe-se a fazer uma avaliação dos diferentes conceitos referentes à modalidade convencional, mais utilizada no Brasil e objeto do presente estudo.

Rizzardo (1997, p.11) conceitua factoring como: 
A relação jurídica entre duas empresas, em que uma delas entrega à outra um título de crédito, recebendo, como contrapartida, o valor constante no título do qual se desconta certa quantia, considerada a remuneração pela transação.

Martins (2000, p. 548) descreve que:

O contrato de faturização ou factoring é aquele em que um comerciante cede a outro os créditos, na totalidade ou em parte, de suas vendas a terceiros, recebendo o primeiro do segundo, o montante desses créditos, mediante o pagamento de uma remuneração.

Nos dois conceitos descritos, observa-se que não é mencionada a prestação de serviços convencionais. Quanto a isto, Donini (2002) alega que tais serviços não precisam estar matrimoniados à cessão de crédito, não caracterizando, com isso, operação bancária (coletar recursos do público, intermediar e emprestar dinheiro). Continuando, informa que, mesmo assim, "na prática, a cessão de crédito divorciada da prestação de serviços é uma exceção, ou seja, eventualmente é utilizada" (DONINI, 2002, p. 732).

Contudo, na Convenção Diplomática de Ottawa, organizada em 1988, pela UNIDROIT, foi estabelecido que a atividade de factoring é executada de forma contínua e pode ser resumida em:

- Prestação de serviços ou de alavancagem mercadológica, ou de seleção e avaliação de riscos, ou de acompanhamento de contas a receber e a pagar;

- Conjugada com a compra de créditos (direitos) de suas empresas-clientes resultantes das vendas mercantis por elas efetuadas ou resultantes da prestação de serviços por elas efetuadas.

Ao reparar que a compra de créditos (direitos) pode ser confundida, para alguns, com o empréstimo bancário contra depósito de duplicatas, Leite (2005) afirma que, na realidade, não há qualquer semelhança com esse tipo de operação financeira, visto que na operação de factoring existe a prestação de serviços e que o negócio (comercial) consiste na venda e na compra de direitos de vendas mercantis.

Ainda que o Brasil não tenha sido signatário da Convenção de Ottawa, ele é membro da UNIDROIT e seus preceitos serviram de inspiração para que, pela primeira vez, fosse incluída a palavra factoring em um texto legal brasileiro, no artigo 28 da Lei n. 8.981/95 (BRASIL, 1995), fato este que foi repetido na Lei n. 9.249/95 (BRASIL, 1995a). Endossando o conceito presente nestes ordenamentos da legislação tributária federal, a Lei n. 9.430/96 consolidou no ordenamento jurídico nacional uma definição mais precisa para a prática do fomento mercantil, quando descreveu, em seu artigo 58, empresas de factoring como sendo aquelas

que explorem as atividades de prestação cumulativa e contínua de serviços de assessoria creditícia, mercadológica, gestão de crédito, seleção e riscos, administração de contas a pagar e a receber, compras de direitos creditórios resultantes de vendas mercantis a prazo ou de prestação de serviços (factoring) (BRASIL, 1996)

Alguns autores (MARTINS, 2000; RIZZARDO, 2000 e DONINI, 2002) têm alegado que o fato de tão somente comprar créditos não enquadra o factoring no artigo 17 da Lei n. 4.595/64 (coletar recurso do público, intermediar e emprestar dinheiro), não constituindo tal operação como um ilícito administrativo criminal.

Sob esta ótica, pode-se até concordar com o fato de que o factoring, como simples compra de crédito, não pode ser enquadrado como instituição financeira; entretanto, também não poderá ser enquadrado no conceito de factoring constante na Convenção de Ottawa. Evento este, que pela sua relevância, serviu de inspiração para a formulação do ordenamento legal brasileiro. 
Uma outra definição, também mais ampla, por abranger diversos serviços, foi dada pelo autor espanhol Roca Guillamón (1977, p. 25), na qual factoring é

uma atividade de cooperação empresarial que tem por objetivo, para o factor, a aquisição, em definitivo, junto aos produtores de bens ou prestadores de serviço, dos créditos de que sejam titulares contra seus clientes ou compradores, garantindo sua satisfação e prestando serviços complementares de contabilidade, estudo de mercado, investigação de clientela etc.

Este conceito, além de contemplar os diversos serviços, fala da aquisição dos créditos "em definitivo", ou seja, a compra é feita pro soluto (o factor assume os riscos, sem o direito de regresso contra a sua empresa-cliente).

Sobre esta outra questão polêmica, que é a assunção de riscos, Assaf Neto (2005) coloca que uma das mais importantes características de uma operação de factoring consiste na transferência, juntamente com os valores a receber, dos riscos inerentes a esses ativos; uma vez que "é considerada, efetivamente, uma transferência (cessão) plena dos créditos do cliente para o factor, isto é, uma aquisição definitiva dos valores a receber, inclusive do risco de pagamento desses ativos realizáveis" (ASSAF NETO, 2005, p. 577).

Cunha e Sá (1989), Comparato (1978), Salamacha (2004) e Wald (1991) ampliam o coro da inexistência de direito de regresso pelas factorings, sendo que Wald (1991, p. 466) apresenta o seguinte conceito:

\begin{abstract}
o contrato de factoring, ou de faturização, consiste na aquisição, por uma empresa especializada, de créditos faturados por um comerciante ou industrial, sem direito de regresso contra o mesmo. Assim, a empresa de factoring, ou seja, o factor, assume os riscos da cobrança e, eventualmente, da insolvência do devedor, recebendo uma remuneração ou comissão, ou fazendo a compra dos créditos com redução em relação ao valor dos mesmos.
\end{abstract}

Por outro lado, Leite (2005, p. 217) alega que as partes poderão acordar livremente a existência ou não da cláusula pro solvendo, que permite à empresa de fomento mercantil o direito de regresso contra a empresa-cliente, em caso de inadimplência do devedor.

Salamacha (2004), Rocha (2007), Lima (2007) e Rizzardo (1997) rechaçam este entendimento ao afirmarem que, mesmo pactuado em contrato, os tribunais têm decidido ser nula cláusula nesse sentido. Salamacha (2004), ao comentar a liberdade que possui o factor de escolher as faturas que o interessam e ofereçam segurança, afirma que "há uma margem de risco pela impontualidade e insolvência do devedor dos créditos cedidos que fica a cargo do faturizador" (SALAMACHA, 2004, p. 88). Rizzardo (1997) expõe factoring como um contrato aleatório (portanto, não bancário), por não ficar o factor com segurança no recebimento do valor constante no título.

Estes argumentos parecem ser bastante convincentes, pois se a empresa de factoring escolhe os títulos que vai adquirir (para evitar contas de difícil recebimento) e se estes são incluídos em um contrato que não caracteriza operação de crédito, não cabe ao factor se eximir dos riscos, seja incluindo a cláusula pro solvendo, seja exigindo garantias e cobrando juros.

Aliás, quanto à exigência de garantias e cobranças de juros, autores que se opõem quanto ao direito de regresso (LEITE, 2005; DONINI, 2002; SALAMACHA, 2004 e COMPARATO, 1978), acabam concordando quanto à impossibilidade destas práticas pelas empresas de factoring, por serem típicas do desconto, empréstimo bancário e abertura de crédito - atividades privativas de instituições financeiras.

Os mesmos autores também concordam quanto às únicas situações em que pode ser dado como certo o direito de regresso contra uma empresa-cliente: créditos inexistentes, de origem ilícita ou créditos irregulares quanto às suas formalidades. 
Não se pode esquecer que, por ser transação comercial legal, faz-se mister a emissão de nota fiscal como prova da prestação dos serviços pela factoring, bem como do valor a ser pago pela empresa-cliente. Reforçando, Leite $(2005$, p. 278$)$ aponta este procedimento como "uma defesa para a companhia de factoring, para que não pairem dúvidas quanto à prática efetiva do factoring e não se dê ensejo a simulações de aplicações financeiras".

O negócio jurídico entre a sociedade de fomento e a empresa-cliente é comprovado pelo contrato de fomento mercantil, que estabelece as condições de relacionamento entre as partes, a prestação de serviços e a compra de títulos de crédito; sendo que estes últimos, a cada operação realizada, devem ser relacionados em borderô anexo, denominado "termo aditivo".

Dentre os principais objetos de negociação pode-se destacar a duplicata e o cheque pré-datado. No Brasil, a duplicata, que por muitos anos permaneceu como o principal título negociado, foi aos poucos sendo preterida pelo vulgarmente chamado cheque "pré-datado". Apesar de não ser legalmente enquadrado como título de crédito, Leite (2005) afirma que se admite a figura do cheque "pré-datado", considerando que a prática da sua utilização em grande escala no mercado é uma realidade incontestável no país, desde que estruturado e vinculado a um documento formal que represente uma legítima transação mercantil entre pessoas jurídicas. Outros títulos de crédito também podem ser negociados, dentre eles, a letra de câmbio, o conhecimento de transporte, o conhecimento de depósito, o warrant e a nota promissória.

\section{Análise de resultados}

Foram obtidos 62 contatos proveitosos, dos quais se constataram que 20 empresas utilizam atualmente, ou utilizaram recentemente, os serviços de factoring (taxa de utilização de $32 \%$ ).

Quando perguntadas sobre os diversos serviços prestados pelas empresas de factoring, dezenove gráficas (95\%) responderam "apenas antecipação de recebíveis" e somente uma (5\%) afirmou haver "antecipação de recebíveis conjugada com avaliação de clientes". Nenhuma outra prestação de serviço (convencional ou diferenciado) foi mencionada.

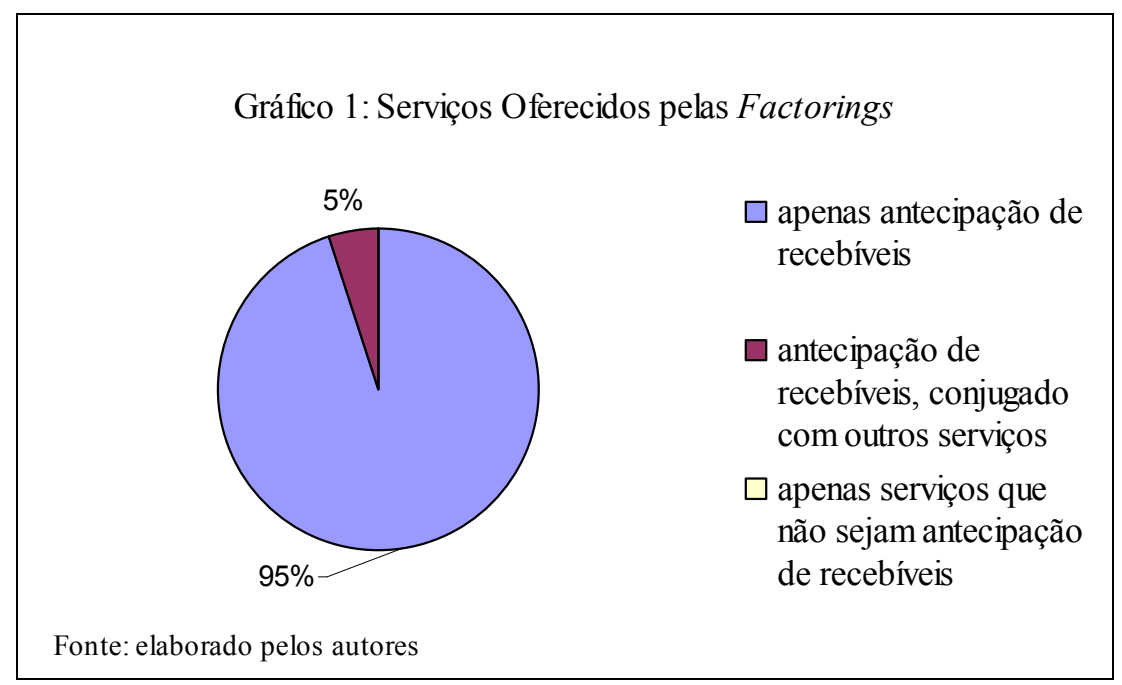

A análise das respostas indica que, de maneira geral, as factorings não prestam serviços de apoio (assessoria e/ou gestão) à sua clientela. Observa-se, então, a ausência da 
prestação "cumulativa" de serviços, prevista na definição de empresas de factoring que está contida na Lei n. 9.430/96 (BRASIL, 1996).

A respeito do direito de regresso, foi buscada a informação sobre quem responderia pelos recebíveis, caso estes não se mostrassem líquidos. $\mathrm{E}$ as respostas foram quase que unânimes (95\%): "Minha empresa responde imediatamente por eles". Ou seja, os factors não assumem os riscos inerentes aos créditos adquiridos.

Gráfico 2: Responsabilidade Perante Inadimplências



empresa-cliente, imediatamente

empresa-cliente, quando a factoring não obtém sucesso na cobrança

factoring assume os riscos

Fonte: elaborado pelos autores

Recapitulando, na década de 80 , as empresas de fomento mercantil se propunham a assumir riscos, sendo que tal atitude contribuiu para que passassem a ser reconhecidas como empresas comerciais, disciplinadas juridicamente pelos princípios do direito mercantil. Além disto, todos os entrevistados informaram que a empresa de fomento mercantil tem total liberdade de escolher os títulos que vai adquirir e, portanto, conseguem reduzir sua exposição ao risco.

Também foram aferidas as características da cessão de crédito (antecipação de recebíveis), onde dezenove (95\%) afirmaram que pagavam taxas superiores às cobradas pelos bancos e apenas uma (5\%) considerou que as mesmas eram equiparadas. Nenhuma gráfica referenciou as taxas das factorings como sendo mais baratas que aquelas cobradas pelos bancos.

\section{Gráfico 3: Taxas cobradas pela factoring}



mais caras do que as dos bancos

mais baratas do que as dos bancos

$\square$ equiparadas aos bancos

Fonte: elaborado pelos autores 
Integrando esta constatação com as duas anteriores, a partir do momento em que não são prestados serviços de apoio e também não são assumidos os riscos, surge a questão: o que tem levado as gráficas a recorrerem às empresas de fomento mercantil? Em um primeiro momento, poderia se achar que as empresas estariam impossibilitadas de recorrerem aos bancos por estarem inadimplentes. Entretanto, dezessete $(85 \%)$ empresas afirmaram preferir as factorings por estarem sempre à disposição (encaminham funcionários até às gráficas) e exigirem menos burocracia, quando comparadas aos bancos. Apenas três (15\%) informaram que recorrem ao factoring para trocar os recebíveis recusados pelo banco.

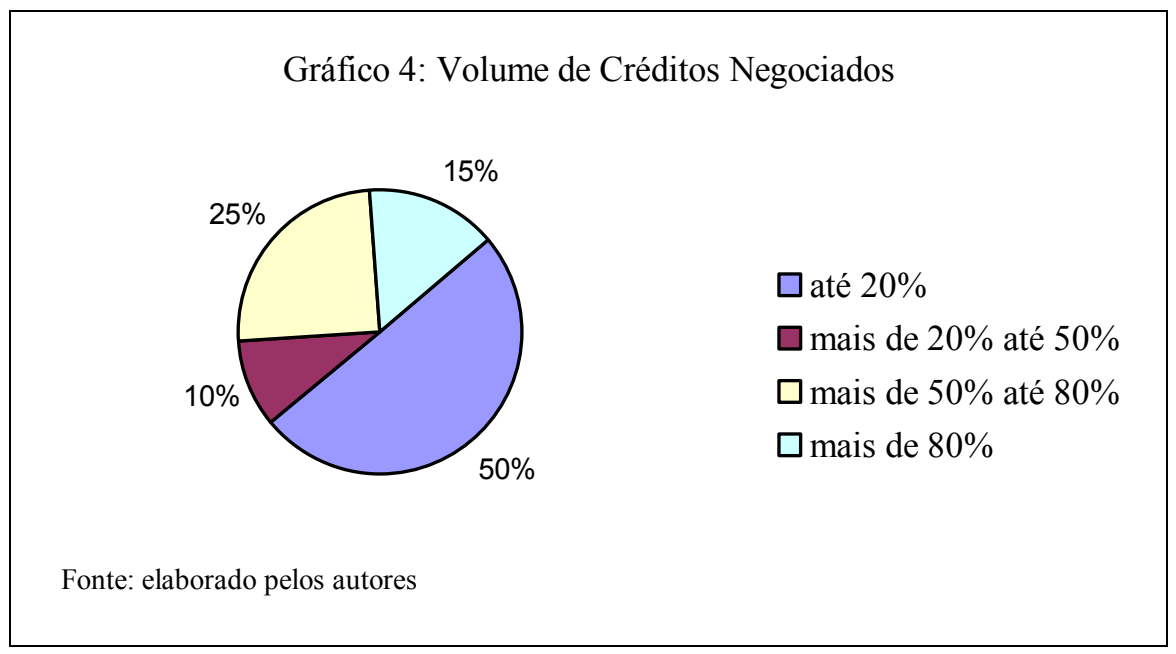

Ao informarem o volume de créditos negociados, dez gráficas afirmaram vender até $20 \%$ do seu faturamento anual, duas, mais de $20 \%$ até $50 \%$, cinco, mais de $50 \%$ até $80 \%$, e três, mais de $80 \%$.

Quanto aos recebíveis geralmente negociados, dezenove disseram tratar-se de duplicatas e/ou cheques pré-datados. Apenas uma mencionou a cessão de notas promissórias. O Gráfico 5 apresenta as respostas obtidas da amostra, cujas empresas tinham a opção de assinalar todos os títulos de créditos que eram efetivamente negociados.

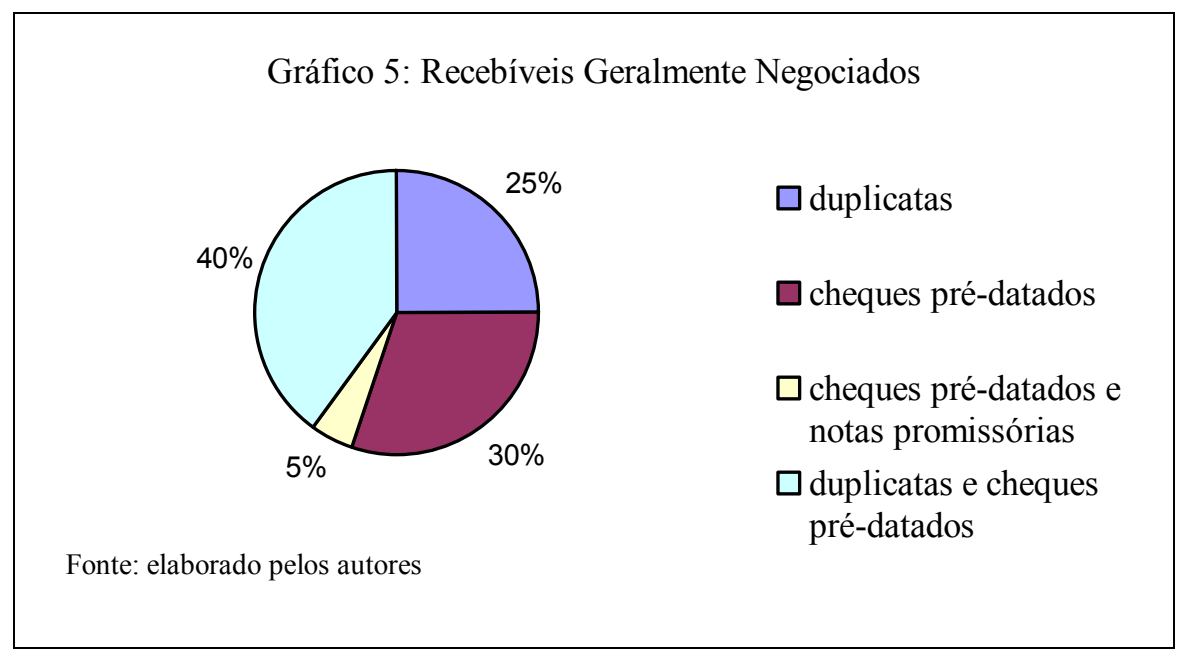


Resumindo, recorrer ao factoring fica mais caro do que recorrer ao banco, os documentos preferidos são os cheques pré-datados e as duplicatas e, geralmente, as empresas negociam menos de $50 \%$ do faturamento.

Quanto às formalidades inerentes às relações comerciais, quando perguntadas sobre a existência de um contrato formal, dezesseis gráficas (80\%) responderam “sim”, quatro $(20 \%)$, "não".

Gráfico 6: Existência de Contrato Formal

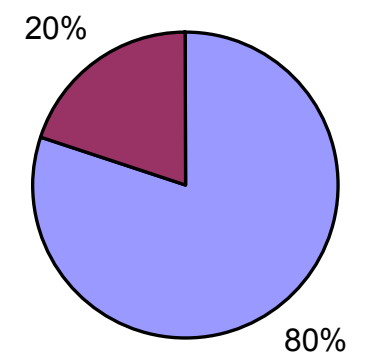

$\square \operatorname{sim}$

$\square$ não

Fonte: elaborado pelos autores

Embora não tenha ocorrido unanimidade, a maioria das empresas cumpriu esta formalidade. Alguns contratos foram analisados e constatou-se que eram bem simples, sem a existência explícita de cláusulas pro soluto ou pro solvendo.

Sobre a emissão de nota fiscal pelas factorings, onze gráficas $(55 \%)$ disseram que não recebem este tipo de comprovante, ao passo que as outras nove $(45 \%)$ afirmaram que as factorings emitem o documento. Ou seja, apesar da nota fiscal comprovar a realização de uma transação comercial legal e, conseqüentemente, ser um documento de emissão obrigatória, a maioria das empresas afirmou que as factorings não a emitem.

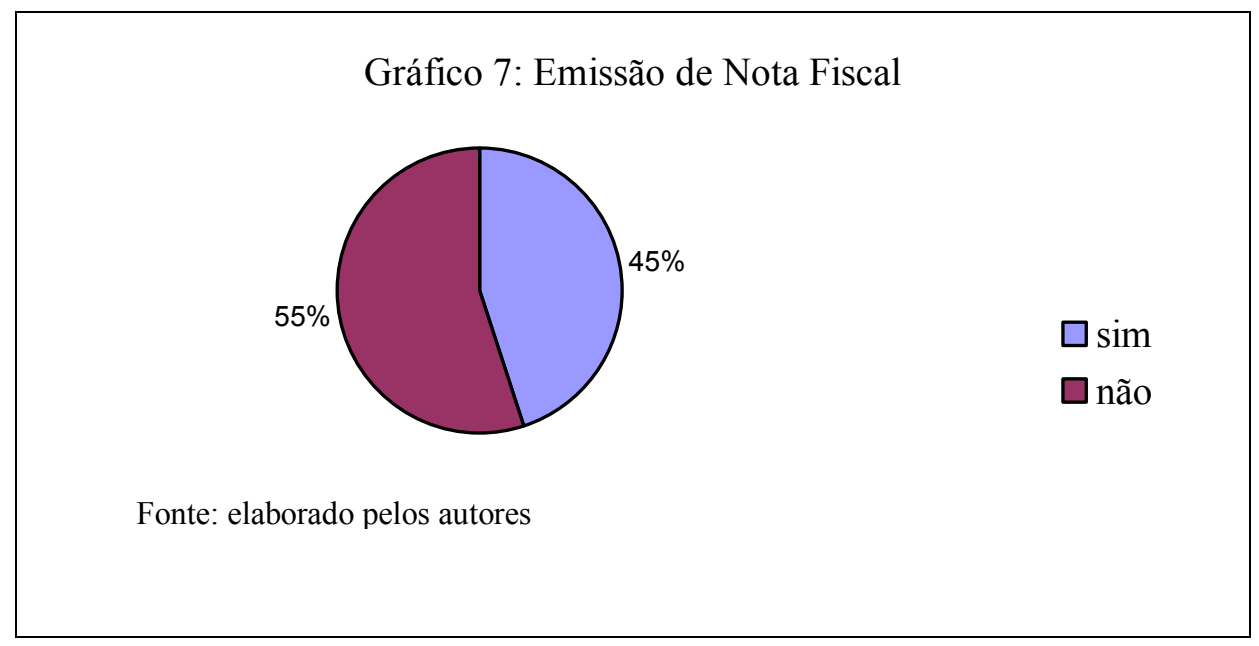

Algumas empresas que afirmaram receber a nota fiscal franquearam, aos pesquisadores, vistas dos documentos e foi interessante notar que todas cobravam comissão ad valorem - cabível apenas quando há prestação de serviços. De acordo com Gráfico 1, apenas uma empresa-cliente deveria ser obrigada a pagar esta receita à factoring, que 
corresponde à contraprestação pelos serviços de apoio, diferentes da simples antecipação de recebíveis.

Importante destacar que algumas gráficas têm sido obrigadas a fornecer garantias que são tipicamente exigidas pelas instituições financeiras. Onze delas (55\%) afirmaram que as factorings exigiram algum tipo de garantia, sendo, em seis casos, notas promissórias, em três, cheque-caução e em dois, algum bem de propriedade da gráfica.

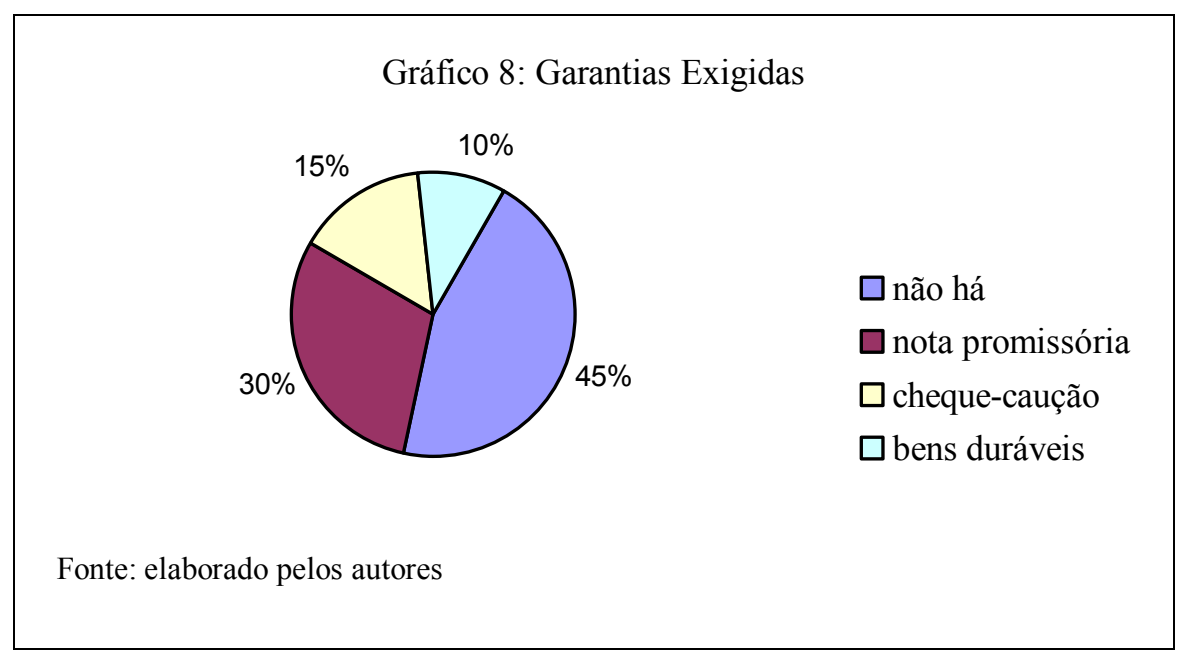

Em suma, quanto às formalidades, observa-se que, apesar de firmado um contrato mercantil, a inexistência de nota fiscal e a exigência de garantias aproxima o factoring, perigosamente, às atividades privativas de instituições financeiras.

\section{Conclusão}

Na opinião de Luz (apud SALAMACHA, 2004, p. 83), "a palavra factoring traz estampada em sua significação praticamente toda a evolução daquilo que ela quer significar". Por isso, o retrospecto histórico ajuda a elucidar uma série de aspectos controversos atuais acerca do modo como este instituto vem sendo praticado.

Desde a Antigüidade até a Revolução Industrial, o factor foi acumulando uma série de funções: intermediário, comerciante, administrador. Por ser profundo conhecedor do mercado local, servia como consultor e era responsável por armazenar e distribuir as mercadorias produzidas nos locais mais distantes. Naquele momento da história não existia a função de fornecedor de recursos, até mesmo porque, no início, nem mesmo havia circulação de moedas.

Somente após a Revolução Industrial foi agregada a função de fornecedor de recursos, mas, diga-se de passagem, apesar de algumas funções terem deixado de existir (armazenador e comerciante), não foram encontrados registros de o factor ter sido, tão somente, fornecedor de recursos. O factoring passou a ser solicitado para adiantar recursos, cuidar da contabilidade e assumir riscos. Há exemplo sim, atualmente, da maioria das empresas do Canadá, onde o factoring não antecipa recursos, mas oferece serviços de garantia de crédito, cobrança e contabilidade.

No Brasil dos anos 1980, diante de um cenário de desemprego e de recessão econômica, o factoring chegou com a proposta de fomentar as micros, pequenas e médias empresas. Inicialmente equiparadas às instituições financeiras, para se livrarem deste enquadramento, enfatizaram a prestação de uma série de serviços, que às descaracterizavam como simples cedentes de crédito, e assumiam todos os riscos pela insolvência do devedor. 
Entretanto, a pesquisa exploratória, ao alcançar o seu objetivo principal, verificou que, na amostra obtida, a maioria das gráficas consultadas não tem acesso aos serviços de apoio (assessoria e/ou gestão) que deveriam estar sendo oferecidos pelas factorings que, tampouco, não assumem os riscos inerentes os créditos adquiridos e oferecem operações com um custo mais elevado dos que as ofertadas pelas instituições financeiras. Em suma, há fortes indícios, na amostra pesquisada, de que as empresas de factoring não têm oferecido contribuições para a redução de alguns dos altos custos aos quais as micros e pequenas empresas brasileiras estão submetidas.

Pelo exposto, identifica-se a necessidade das empresas-clientes reavaliar se a facilidade no adiantamento de recursos, com taxas superiores aos dos bancos e sem livrar-se dos riscos, realmente traz mais vantagens do que desvantagens. Para o setor de factoring há a opção de rever seu papel, sob o risco de perda da relevância de sua participação na matriz de financiamento em um País cuja estabilidade macroeconômica tem a capacidade potencial de proporcionar, cada vez mais, acesso a crédito em maior abundância e menos caro.

Para as próximas investigações, recomenda-se analisar outros setores relevantes que sejam compostos, em sua maioria, por micros e pequenas empresas. A busca de uma amostra superior à apresentada nesta investigação possibilitará a utilização de estatística mais robusta, cujos resultados obtidos - mais consistentes - favorecerão, inclusive, a generalização.

\section{Referências}

ASSAF NETO, Alexandre. Finanças Corporativas e Valor. 2. ed. São Paulo: Atlas, 2005.

BANCO CENTRAL DO BRASIL. Circular n. 703, de 16 de junho de 1982. Brasília, 1982.

. Circular n. 1.359, de 30 de setembro de 1988. Brasília, 1988.

BANERJEE, P. K. Global factoring business: trend and performance. Delhi: Finance India, 2003.

BRASIL. Lei n. 4.595, de 31 de dezembro de 1964. Lei do Sistema Financeiro Nacional. Dispõe sobre a política e as instituições monetárias bancárias e creditícias, cria o Conselho Monetário Nacional e dá outras providências. Diário Oficial [da] República Federativa do Brasil. Brasília, DF, 31 dez. 1964. Disponível em http://www.senado.gov.br>. Acesso em 2 jun. 2007.

Constituição da República Federativa do Brasil, de 5 de outubro de 1988. Diário Ofícial [da] República Federativa do Brasil. Brasília, DF, 5 out. 1964. Disponível em $<$ http://www.senado.gov.br>. Acesso em 14 de jun. 2007.

Lei n. 8.981, de 20 de janeiro de 1995. Altera a legislação tributária federal e dá outras providências. Diário Oficial [da] República Federativa do Brasil. Brasília, DF, 23 jan. 1995. Disponível em <http://www.senado.gov.br>. Acesso em 2 jun. 2007.

. Lei n. 9.249, de 26 de dezembro de 1995. Altera a legislação do imposto de renda das pessoas jurídicas, bem como da contribuição social sobre o lucro líqüido, e dá outras providências. Diário Oficial [da] República Federativa do Brasil. Brasília, DF, 27 dez. 1995. Disponível em $<$ http://www.senado.gov.br>. Acesso em 2 jun. 2007.

Lei n. 9.430, de 27 de dezembro de 1996. Dispõe sobre a legislação tributária federal, as contribuições para a seguridade social, o processo administrativo de consulta e dá outras providências. Diário Oficial [da] República Federativa do Brasil. Brasília, DF, 30 dez. 1996. Disponível em $<$ http://www.senado.gov.br>. Acesso em 2 jun. 2007.

COMPARATO, Fábio Konder. Ensaios e Pareceres de Direito Empresarial. Rio de Janeiro: Forense, 1978. 
CORRÊA. Paulo Henrique da Costa. Um Estudo de Caso sobre as Empresas de Factoring no Estado do Espírito Santo. Dissertação de Mestrado - EBAPE/FGV, Rio de Janeiro, 2004.

CUNHA E SÁ, Gonçalo Ivens Ferraz da. O Factoring e a Nova Constituição. Revista do Direito Mercantil. São Paulo: Malheiros, v. 73, jan.-março 1989.

DODL. Alessandra Von Borovski. A Atividade de Factoring no Mercado Brasileiro. Dissertação de Mestrado em Desenvolvimento Econômico - UFPR, Paraná, 2006.

DONINI, Antônio Carlos. Factoring: regulação, funções desempenhadas, modalidades e o direito de regresso. Revista dos Tribunais, São Paulo, v. 802, p. 727-748, ag. 2002.

FCI - Factors Chain International. Disponível em $<$ http://www.factors-chain.com>. Acesso em 18 jun. 2007.

GREMAUD, A. P.; VASCONCELLOS, M. A. S. de; TONETO JÚNIOR, R. Economia brasileira contemporânea. 4. ed. São Paulo: Atlas, 2002.

HILLYER. Origin of factoring. Londres: Barron's, 1941.

HORNGREN, Charles T.; DATAR, Srikant M. e FOSTER, George. Contabilidade de Custos: uma abordagem gerencial. 11. ed. São Paulo: Prentice Hall, 2005.

IBGE - Instituto Brasileiro de Geografia e Estatística. As micro e pequenas empresas comerciais e de serviços no Brasil - 2001. Rio de Janeiro: IBGE, 2003.

KUMAR, A. (A study led by). Access to Financial Services in Brazil. Banco Mundial, 2005.

LEITE, Luiz Lemos. Factoring no Brasil. 10. ed. São Paulo: Atlas, 2005.

LIMA, Antônio César Barros de. Sobre o Direito de Regresso e o Direcionamento Atual do Factoring. Disponível em $<$ http://www.direitonet.com.br/artigos/x/20/16/2016/> . Acesso em 14 jun. 2007.

MAHAR, Margareth. Factoring: no bed of roses for the banks. Nova Iorque: Citybusiness, 1984.

MARTINS, Fran. Contratos e obrigações comerciais. 7 ed. Rio de Janeiro: Forense, 2000.

RIZZARDO, Arnaldo. Factoring. São Paulo: RT, 1997.

ROCA GUILLAMÓN, Juan. El contrato de factoring y su regulación por el derecho privado español. Madrid: Ed. Revista de Derecho Privado, 1977.

ROCHA, Marcelo Hugo da. Estudo sobre o Contrato de Factoring. Disponível em $<$ http://jus2.uol.com.br/doutrina/texto.asp?id=634>. Acesso em 12 jun 2007.

SALAMACHA. O Factoring como Instrumento de Auxílio às Pequenas e Médias Empresas. Revista dos Tribunais, São Paulo, v. 822 p. 79-105, abril 2004.

SEBRAE - Serviço Brasileiro de Apoio às Micro e Pequenas Empresas. Fatores condicionantes e taxa de mortalidade de empresas no Brasil. Brasília: SEBRAE, 2004.

SILVA. Eduardo Menezes da. Análise da Evolução das Operações de Factoring. Dissertação de Mestrado - ESASP/FGV, São Paulo, 1995.

VERGARA, Sylvia Constant. Projetos e Relatórios de Pesquisa em Administração. 4. ed. São Paulo: Atlas, 2003.

WALD, Arnoldo. Curso de Direito Civil. São Paulo: RT, v. II, p. 466, 1991. 